\title{
Numerical Simulation of Char Particle Gasification
}

\author{
Syed Shabbar Raza ${ }^{1}$, Isam Janajreh ${ }^{1}$, Rizwan Ahmed ${ }^{2}$ and Ashjan AlKatheeri ${ }^{2}$ \\ 1. Waste to Energy Lab, Masdar Institute of Science and Technology, Abu Dhabi 54224, UAE \\ 2. Takreer Research Center, Abu Dhabi 3593, UAE
}

Received: June 15, 2015 / Accepted: July 17, 2015 / Published: August 31, 2015.

\begin{abstract}
A first principal modeling of the gasification of a char particle is performed using single step mechanism. The char particle is considered to be spherical in shape and only the physical and chemical properties can change in the radial direction. The carbon dioxide is used as the gasification agent that reacts with the char and form carbon monoxide. The presence of both solid and gaseous phase species makes the reaction heterogeneous. The char particle is considered with varying porosity that also allows the change in the surface area of the particle. A time invariant temperature and pressure profile is used at which the Arrhenius rate constant and diffusion is calculated. The mass conservation of model results in the form of two coupled partial differential and one ordinary differential equation. The equations are solved with a set of initial and boundary conditions using the bulk species concentration at the particle surface. A second order accurate central differencing scheme is used to discretize space while backward differencing is used to discretize time. Finally, the results are presented for the concentration distribution of $\mathrm{CO}$ and $\mathrm{CO}_{2}$ in radial direction with respect to time. It shows that, maximum concentration of $\mathrm{CO}$ is present at the center of the particle while the concentration gradient becomes higher near the particle surface. The nonlinear concentration trend due to the diffusion is effectively captured. The results show that, completed conversion of char depend upon the time provided for the reaction which can be reduced by decreasing the size of particle or increasing the reaction temperature. The sensitivity study of temperature and initial porosity also performed and showed that temperature has high impact on char conversion as compare to initial porosity.
\end{abstract}

Key words: Coal, particle conversion, biomass, porosity, $\mathrm{CO}_{2}$ gasification.

\section{Introduction}

Char gasification is one of the important processes to generate fuel, electricity and variety of chemical. Char is normally generated by de-volatalizing coal or biomass at high temperature to remove its moisture and volatile contents [1]. Then this porous char can be reacted with gasification agent i.e., air, oxygen, steam, $\mathrm{CO}_{2}$ etc. to produce a useful syngas product, i.e., $\mathrm{CO}$ and $\mathrm{H}_{2}$. Ash is also a compulsory part of the char and its quantity depends upon the type of coal or biomass used to produce the char.

Char can be derived from any carbonaceous material that includes mainly coal and biomass. The primary constituent of char is carbon and it is directly related to the amount of carbon present in the carbonaceous

Corresponding author: Isam Janajreh, associate professor, research fields: chemical reaction engineering, gasification, computational mechanics and aerodynamics. E-mail: ijanajreh@masdar.ac.ae. material. Fig. 1 shows the $\mathrm{H} / \mathrm{C}$ and $\mathrm{O} / \mathrm{C}$ ratios for coal, lignite, peat and biomass. It is clearly evident from the figure that both $\mathrm{H} / \mathrm{C}$ and $\mathrm{O} / \mathrm{C}$ ratios for coal are lower than that off the biomass and as a results a higher heating value according to Channiwala's formula [2]. It means that, coal have high percentage of carbon present as compare to biomass. The ultimate analysis for coal and biomass presented in Table 1 which carried elsewhere [3] demonstrate the higher percentage of carbon in coal as compare to pine needle biomass.

But this high percentage of carbon is not the only criteria to select coal or the other feedstock for the high yield of char. As the char represents the solid form of carbon, therefore it is necessary to know the percentage of solid or fixed carbon presents in coal and biomass. Table 2 shows the proximate analysis (as received) of coal and biomass that fraction the feedstock into 


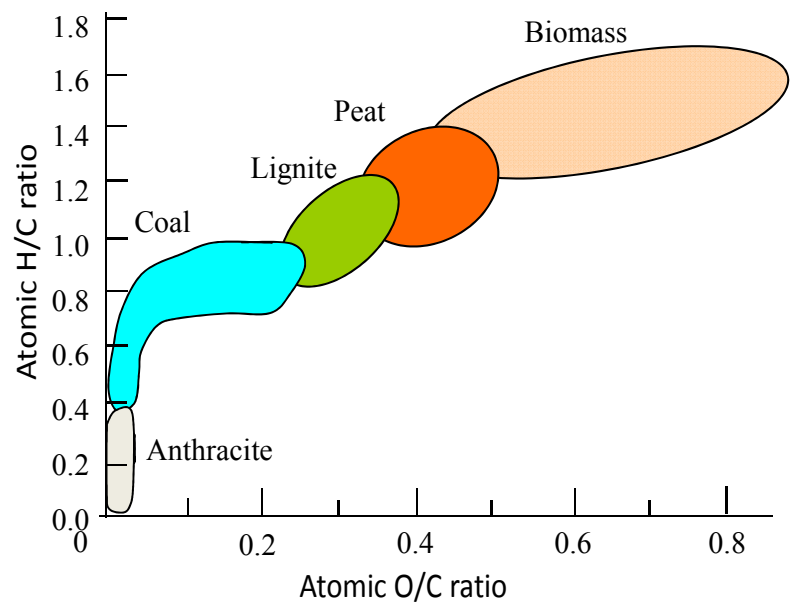

Fig. 1 Van Krevelen diagram.

Table 1 Ultimate analysis of coal and biomass.

\begin{tabular}{lll}
\hline & Coal & Pine needles \\
\hline Cwt.\% & 82.17 & 48.58 \\
H wt.\% & 5.60 & 6.30 \\
O wt.\% & 8.60 & 43.64 \\
N wt.\% & 2.50 & 1.48 \\
S wt.\% & 1.13 & 0 \\
\hline
\end{tabular}

Table 2 Proximate analysis of coal and biomass (as received).

\begin{tabular}{lll}
\hline & Coal & Pine needles \\
\hline Moisture wt.\% & 0.30 & 9.01 \\
Volatile wt.\% & 37.81 & 44.58 \\
Fixed carbon wt.\% & 54.65 & 42.28 \\
Ash wt.\% & 7.22 & 4.12 \\
\hline
\end{tabular}

moisture, volatiles, fixed carbon and ash fractions that present in the sample.

The result of proximate analysis shows the higher percentage of fixed carbon present in coal as compare to biomass. This clearly indicates this tested grade of coal as a better choice to produce high quantity char per unit weight of feedstock. On other hand, biomass exhibit higher quantity of volatile material which is expected to yield a high porous char as biomass particle agglomerate, baked, through the de-moisturization and de-volatilization processes. This high porosity provides more surface area inside the pores for reaction to occur. Therefore, it is kind of trade-off to produce char using fixed-carbon rich coal or high-volatile biomass.

The modelling of coal de-volatilization, combustion and gasification in the form comprehensive model and CFD (computational fluid dynamic) code are already performed in Waste to Energy Lab at Masdar Institute, Abu Dhabi with variety of different feedstock [3-9]. The similar modelling techniques that are used for coal or biomass cannot be used directly for char due to the large difference in the physical and chemical properties. Reaction kinetics of char is much simpler than coal/biomass as its main composition is carbon.

A considerable amount of literature is available in which gasification of char is presented. Kim, et al. [10] prepared char from 12 different bituminous coals at different reaction temperature for the gasification with $\mathrm{CO}_{2}$ under isothermal conditions. The concentration of $\mathrm{CO}$ and $\mathrm{CO}_{2}$ measured using online gas analyser. The results show that, the reactivity is increased as the particle size decreases at the given temperature. Modelling of char gasification performed that accounts for the shrinking core model better for large particle size while the volumic reaction model is also more suitable for smaller particle size. Singer, et al. [11] developed an adaptive random pore model for the application to the char gasification. This model allows different pore sizes to grow at different rates at a given location within a reacting porous particle. The model satisfactory reproduce some coal char oxidation experiments from the literature, however because of the complexity of the model no attempt to integrate it to reactive flow environment is pursued. Seo, et al. [12] use volume of reaction model, shrinking core model and random pore model to interpret the experimental data for biomass char $\mathrm{CO}_{2}$ gasification. The result presented in term of $\mathrm{CO}$ and $\mathrm{CO}_{2}$ yield at different operating conditions. The final comparison shows that, random pore model agreed with the experimental data more than the other two models. Suresh, et al. [13] performed palm shell char gasification using $\mathrm{CO}_{2}$ through TGA (thermo gravimetric analyser) at temperature ranging from $800{ }^{\circ} \mathrm{C}$ to $1,000{ }^{\circ} \mathrm{C}$. Four different models are used to identify the correct pattern of experimental data and based on RMSE (root mean 
square error) the random pore model is found in good agreement with the data.

In this research study, an attempt is made to build a model for char particle gasification. The main motivation behind modelling is to develop a simplified approach so that it can further integrate with commercial CFD software at low computational expenses. This integration will help to run the large number of discrete particle simulation in a single step. The model used in this study comprise of a single heterogeneous reaction which represent the $\mathrm{CO}_{2}$ gasification. A constant value of temperature and pressure is used throughout the domain. Finally, the results are presented in term of the yield of $\mathrm{CO}$ and $\mathrm{CO}_{2}$.

\section{Physical and Computational Model}

Gasification is a complex process that occurs inside the pores of the particle. There are several chemical and physical processes taking place inside the particle. The reactants diffuse inside the particle and reacts with the char and multiple heterogeneous and homogeneous reactions occur. Due to the reaction, the size and shape of the pores are continuously changing which also change the physical shape of the char particle. Combining both chemical and physical process makes the char gasification quite complex and hence the need of modelling this process is necessary for understanding the evolution of the syngas species.

By considering char as coal or biomass, a primary gasification reaction can be written as follow:

$$
\begin{gathered}
\mathrm{CH}_{x} \mathrm{O}_{y} \mathrm{~N}_{z}+l\left(\mathrm{O}_{2}+3.76 \mathrm{~N}_{2}\right)+m \mathrm{H}_{2} \mathrm{O}+ \\
n \mathrm{CO}_{2} \rightarrow x_{1} \mathrm{CO}+x_{2} \mathrm{H}_{2}+x_{3} \mathrm{CH}_{4}+x_{4} \mathrm{CO}_{2} \\
+x_{5} \mathrm{H}_{2} \mathrm{O}+3.76 l \mathrm{~N}_{2}
\end{gathered}
$$

where, $x, y, z$ and $l, m, n, x_{1}, x_{2}, x_{3}, x_{3}$ and $x_{5}$ are the respective moles of each element and component per mole of carbon in the system.

The above reaction shows that, gasification can be achieved by using the combination of air, $\mathrm{H}_{2} \mathrm{O}$ and $\mathrm{CO}_{2}$ as oxidizer and moderator, but, it is not necessary, either anyone of them can be used. This primary gasification reaction can be split into numbers of intermediate reaction and the most important reaction are given below:

char reforming:

$$
\mathrm{C}+\mathrm{H}_{2} \mathrm{O}=\mathrm{CO}+\mathrm{H}_{2}+131 \frac{M J}{\text { Kmole }}
$$

boudouard reaction:

$$
\mathrm{C}+\mathrm{CO}_{2}=2 \mathrm{CO}+172 \frac{\mathrm{MJ}}{\text { Kmole }}
$$

methane cracking-hydro gasification:

$$
\mathrm{C}+2 \mathrm{H}_{2}=\mathrm{CH}_{4}-75 \frac{\mathrm{MJ}}{\text { Kmole }}
$$

methane reformation:

$$
\mathrm{CH}_{4}+\mathrm{H}_{2} \mathrm{O}=\mathrm{CO}+3 \mathrm{H}_{2}+206 \frac{M J}{\text { Kmole }}
$$

water gas shift reaction:

$$
\mathrm{CO}+\mathrm{H}_{2} \mathrm{O}=\mathrm{CO}_{2}+\mathrm{H}_{2}-41 \frac{M J}{\text { Kmole }}
$$

In this study, the physical model is based on the gasification of a char particle. The char particle normally is the yield of high temperature devolatilization of coal or biomass particle. These particles have porous structure throughout. The reactant moves inside the pores during the reaction and product species move outside. The heterogeneous reaction takes place at the surface of the particle while the homogenous reaction occurs inside the pores and outside the particle.

To develop a simplified model only a heterogeneous reaction is considered that represents the $\mathrm{CO}_{2}$ gasification of the char particle, as given by Eq. (3). This reaction is commonly known as boudouard reaction and represents the gasification of char by carbon dioxide.

Eq. (3) shows one solid phase (C/char) and two gas phase species $\left(\mathrm{CO}\right.$ and $\left.\mathrm{CO}_{2}\right)$. The governing equations to model the physical system of gasification can be represented by mass conservation in both solid and gas phase reaction, as given below:

$$
\frac{\partial\left(\phi C_{\mathrm{CO}}\right)}{\partial \mathrm{t}}=\frac{1}{r^{2}} \frac{\partial}{\partial r}\left(r^{2} D_{e f f}(\phi) \frac{\partial C_{\mathrm{CO}}}{\partial \mathrm{r}}\right)+f_{1}\left(C_{\mathrm{CO}_{2}}, C_{\mathrm{CO}}, \phi\right)
$$




$$
\begin{gathered}
\frac{\partial\left(\phi C_{\mathrm{CO}_{2}}\right)}{\partial t}=\frac{1}{r^{2}} \frac{\partial}{\partial r}\left(r^{2} D_{e f f}(\phi) \frac{\partial C_{\mathrm{CO}_{2}}}{\partial r}\right)+f_{2}\left(C_{\mathrm{CO}_{2}}, \phi\right) \\
\frac{\mathrm{d} X}{\mathrm{~d} t}=f_{3}\left(C_{\mathrm{CO}_{2}}, \phi\right)
\end{gathered}
$$

where, $\phi$ represents the porosity of the particle; $C_{i}$ represents the concentration of gas phase species; $r$ and $t$ represents the radial and time coordinate, respectively; $D_{\text {eff }}$ represents the effective diffusivity; $f_{i}$ represents the source term due to reaction and $X$ represents the conversion of char. Eqs. (7) and (8) represent partial differential equation showing the reaction-diffusion model for the gas phase species. Eq. (9) represents an ordinary differential equation for the conversion of char.

The porosity of the particle can be represented in term of initial porosity $\left(\phi_{0}\right)$ and char conversion, and is written as:

$$
\phi(r, t)=\phi_{0}+\left(1-\phi_{0}\right) X(r, t)
$$

Similarly the effective diffusion is given as,

$$
D_{e f f}(r, t)=D \phi^{2}(r, t)
$$

The reaction source term is given as,

$$
f_{i}=\left(1-\phi_{0}\right) S k_{r x n} C_{\mathrm{CO}_{2}} v_{i}
$$

where, $v_{i}$ is the stoichiometric coefficient; $S$ is the surface area; $k_{r x n}$ is the Arrhenius rate constant i.e., $k_{r x n}=4364 \mathrm{e}^{-\frac{29844}{T}} ; T$ is the temperature (K). The surface area of the particle is represented by its initial surface area $\left(S_{0}\right)$ and the char conversion:

$$
S=S_{0}(1-X(r, t))
$$

By substituting Eqs. (10)-(13) in Eqs. (7)-(9) and after simplification the following equations are written as:

$$
\begin{gathered}
\left(\left(1-\phi_{0}\right) X(r, t)+\phi_{0}\right) \frac{\partial C_{\mathrm{CO}}}{\partial t}= \\
\frac{1}{r^{2}} \frac{\partial}{\partial r}\left(r^{2} D\left(\left(1-\phi_{0}\right) X(r, t)+\phi_{0}\right)^{2} \frac{\partial C_{\mathrm{CO}}}{\partial r}\right)+ \\
C_{\mathrm{CO}_{2}} k_{r n x} S_{0}(1-X(r, t))\left(1-\phi_{0}\right) \\
\left(v_{\mathrm{CO}}+\frac{M_{\mathrm{c}} C_{\mathrm{CO}}}{\rho_{\mathrm{C}}\left(1-\phi_{0}\right)} v_{\mathrm{C}}\right)
\end{gathered}
$$

$$
\begin{gathered}
\left(\left(1-\phi_{0}\right) X(r, t)+\phi_{0}\right) \frac{\partial C_{\mathrm{CO}_{2}}}{\partial t}= \\
\frac{1}{r^{2}} \frac{\partial}{\partial r}\left(r^{2} D\left(\left(1-\phi_{0}\right) X(r, t)+\phi_{0}\right)^{2} \frac{\partial C_{\mathrm{CO}_{2}}}{\partial r}\right)+ \\
C_{\mathrm{CO}_{2}} k_{r n x} S_{0}(1-X(r, t))\left(1-\phi_{0}\right) \\
\left(v_{\mathrm{CO}_{2}}+\frac{M_{\mathrm{c}} C_{\mathrm{CO}_{2}}}{\rho_{\mathrm{C}}\left(1-\phi_{0}\right)} v_{\mathrm{C}}\right) \\
\frac{\mathrm{d} X(r, t)}{\mathrm{d} t}=-\frac{M_{\mathrm{c}}}{\rho_{\mathrm{c}}} v_{\mathrm{c}} k_{r x n} S_{0}(1-X(r, t)) \mathrm{C}_{\mathrm{CO}_{2}}
\end{gathered}
$$

where, $M_{\mathrm{c}}$ is the molecular weight of carbon and $\rho_{\mathrm{C}}$ is its density. The diffusion is calculated using the Reid's formula [14] and is given as:

$$
D=\frac{\left(1 \times 10^{-7} T^{1.75}\right)}{\text { Pressure } \times\left(A D_{\left.C O^{\frac{1}{3}}+A D_{\mathrm{CO}_{2}}^{\frac{1}{3}}\right)^{2}}\right.} \sqrt{\frac{\left(M W_{\mathrm{CO}}+M W_{\mathrm{CO}_{2}}\right)}{M W_{\mathrm{CO}} \times M W_{\mathrm{CO}_{2}}}}
$$

where, $A D$ is the atomic diffusion for the gases.

The values of the constants used in Eqs. (14)-(17) are given in Table 3.

\section{Initial Conditions and Boundary Conditions}

Eqs. (14)-(16) give us to represent a system of two coupled partial differential equations and one ordinary differential equation. As the particle is assumed to be perfectly spherical and all physical properties are either constant or changing in the radial direction. To solve the differential equations, a set of initial and boundary conditions are used. Dirichlet/symmetry (zero gradient) boundary condition is used at the center $(r=0)$ while Neumann boundary condition is used at the surface $(r=$ $R$ ) and are written as:

$$
@ r=0 \quad \frac{\partial c_{i}(0, t)}{\partial r}=0
$$

$@ r=R, C_{\mathrm{CO}}(R, t)=100 \frac{\mathrm{mol}}{\mathrm{m}^{3}}$ and $C_{\mathrm{CO}_{2}}=50 \frac{\mathrm{mol}}{\mathrm{m}^{3}}$

The boundary condition of Eq. (14) is actually the gasification condition calculated at temperature and pressure mentioned in Table 3. The initial conditions are taken as uniform values of gas species concentration mentioned in Eq. (19). A second order central difference scheme is used to solve the equation in space and backward marching scheme is used for the time. 
Table 3 Value of the constants used in Eqs. (7)-(17).

\begin{tabular}{lll}
\hline Name & Unit & Value \\
\hline$\phi_{0}$ & - & 0.2 \\
$S_{0}$ & $\mathrm{~m}^{2} / \mathrm{m}^{3}$ & $2,267 \mathrm{E} 5$ \\
$M_{\mathrm{c}}$ & $\mathrm{gm} / \mathrm{mol}$ & 12 \\
$\rho_{\mathrm{c}}$ & $\mathrm{kg} / \mathrm{m}^{3}$ & 2,267 \\
$v_{\mathrm{C}}$ & - & 1 \\
$v_{\mathrm{CO}}$ & - & 2 \\
$v_{\mathrm{CO}_{2}}$ & - & 1 \\
$M W_{\mathrm{CO}}$ & $\mathrm{gm} / \mathrm{mol}$ & 28 \\
$M W_{\mathrm{CO}_{2}}$ & $\mathrm{gm} / \mathrm{mol}$ & 44 \\
$A D_{\mathrm{CO}}$ & $\mathrm{cm} / \mathrm{s}$ & 18.9 \\
$A D_{\mathrm{CO}_{2}}$ & $\mathrm{~cm} / \mathrm{s}$ & 26.9 \\
$T$ (temperature) & $\mathrm{K}$ & 1,600 \\
$P$ (pressure) & $\mathrm{atm}$ & 20 \\
$R$ & $\mu \mathrm{m}$ & 100 \\
\hline
\end{tabular}

\section{Results and Discussion}

The mass conservation of $\mathrm{CO}$ and $\mathrm{CO}_{2}$ is depending upon the diffusion and the source terms due to the Arrhenius base kinetics. As the temperature of the particle is held constant this in turns makes the $k_{r x n}$ a constant in Eqs. (14)-(16). Also, the diffusion calculated from Eq. (17) is constant throughout the simulation. These assumptions make the problem quite simpler and only the concentration of gases and char conversion left as the unknowns.

The result of the concentration of CO is given in Fig. 2. It shows that, initially, the concentration of particle maintain profile having the concentration of around $200 \mathrm{~mol} / \mathrm{m}^{3}$ at the particle center. As the time progress, the concentration of $\mathrm{CO}$ decrease and reach to a value of $100 \mathrm{~mol} / \mathrm{m}^{3}$ at the end of the simulation time. This is because the temperature of the particle is maintained at a constant value which makes a constant diffusion flux outside the particle, eventually when all char is converted into $\mathrm{CO}$ the bulk value concentration of $\mathrm{CO}$ propagate inside the particle.

Fig. 3 shows the $\mathrm{CO}_{2}$ concentration inside the particle. It shows that, as the simulation starts the concentration of $\mathrm{CO}_{2}$ suddenly decrease to a minimum value of nearly zero at the center of particle. This is because of the high conversion of $\mathrm{CO}_{2}$ and char into CO. As the boundary of particle having a fixed concentration of $\mathrm{CO}_{2}$, therefore, it forces the solution to maintain that value all the time. When almost all the char depleted the concentration of $\mathrm{CO}_{2}$ inside the particle becomes the bulk concentration.

Fig. 4 shows the char conversion along the radial direction. It clearly shows the increase in conversion

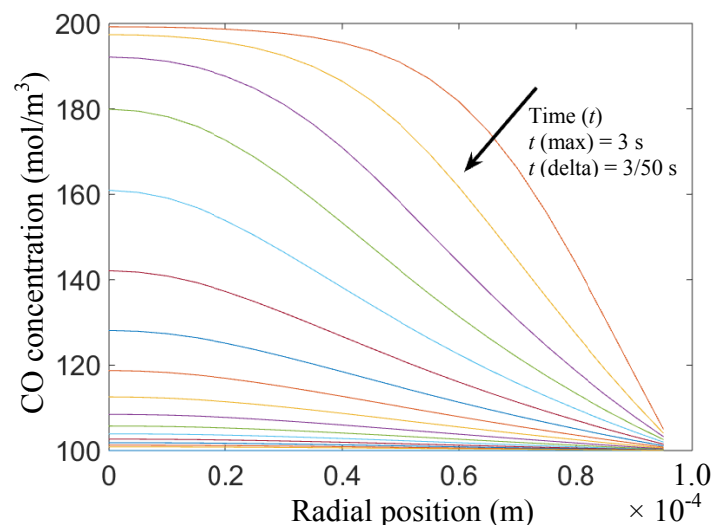

Fig. 2 CO concentration along radial direction as time is progressing.

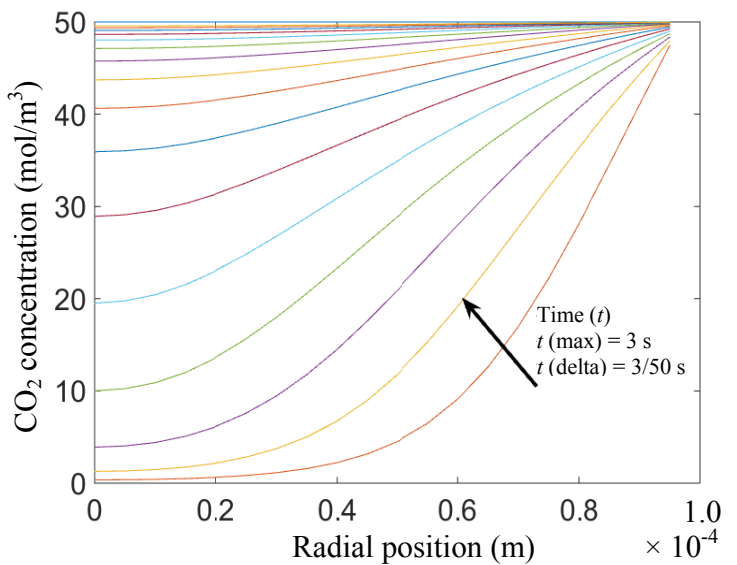

Fig. $3 \mathrm{CO}_{2}$ concentration along radial direction as time is progressing.

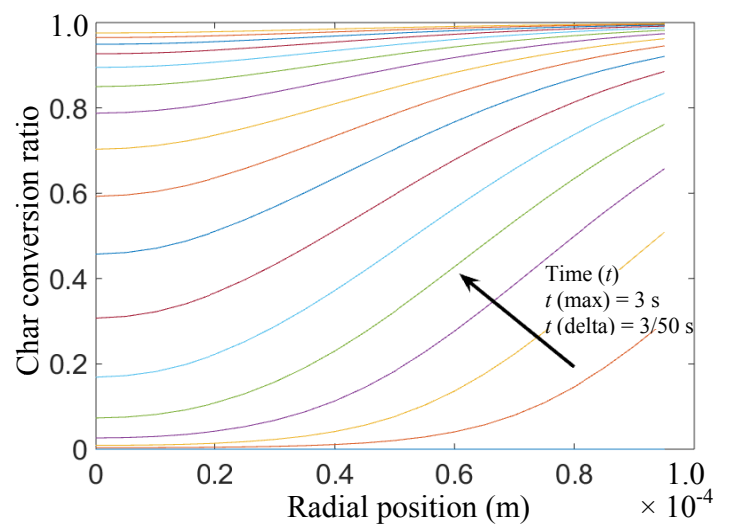

Fig. 4 Char conversion along the radial direction as the time is progressing. 
with the simulation time. The total simulation time is $3 \mathrm{~s}$ which is sufficiently long, but not enough to ensure all the char present in the particle is fully converted into CO. Also, the steeper curve near the surface of the particle shows that, the conversion of char also depends upon the size of the particle. If the size of the particle is taken smaller complete char conversion can be achieved in a lesser time.

The sensitivity study of temperature is also performed to show the effect of temperature on char conversion. For that purpose, an increasing temperature is applied for the time duration of $3 \mathrm{~s}$ and presented in Figs. 5 and 6. The temperature sensitivity is performed using the 10 different jumps starting from $1,000 \mathrm{~K}$ to $2,000 \mathrm{~K}$ and the end result of the simulation is presented.

Fig. 5 shows the $\mathrm{CO}$ concentration along radial direction as function of the temperature increase. It shows that, the temperature is directly proportional to the $\mathrm{CO}$ concentration i.e., as the temperature increase, the concentration of $\mathrm{CO}$ concentration is also increase. The concentration of $\mathrm{CO}$ at the outer surface is constant, due to the fixed boundary condition. Similarly, Fig. 6 shows the $\mathrm{CO}_{2}$ concentration along the radial direction as temperature increases. It shows that, as the temperature increase, the concentration of $\mathrm{CO}_{2}$ decrease. It is due to the fact that, the increasing temperature directly affects the Arrhenius rate constant and because only forward reaction is considered therefore the $\mathrm{CO}_{2}$ concentration decrease.

Fig. 7 shows the char conversion along the radial direction with respect to the temperature. It shows that, temperature has a high effect on the conversion of char particle. As the temperature increase the more char is reacted with the $\mathrm{CO}_{2}$ in the simulation time of $3 \mathrm{~s}$.

Any decrease in the reaction temperature is associated with substantial decrease in the char conversion.

Fig. 8 shows the $\mathrm{CO}$ concentration along the radial direction for the sensitivity analysis of initial porosity. The simulation time and temperature is kept similar to baseline case i.e., $3 \mathrm{~s}$ and 1,600 K. The result shows that, the change of porosity has impact on $\mathrm{CO}$ concentration. Although the scale of this impact is considerably less those of the temperatures change. It shows that, as the porosity decrease, the $\mathrm{CO}$ concentration increase. It is due to the fact that, the decrease porosity increases the amount of char present

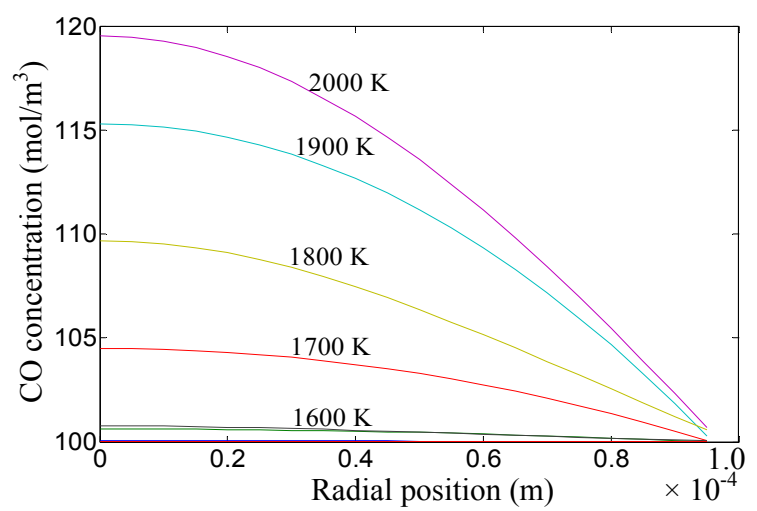

Fig. $5 \mathrm{CO}$ concentration along radial direction as temperature increases.

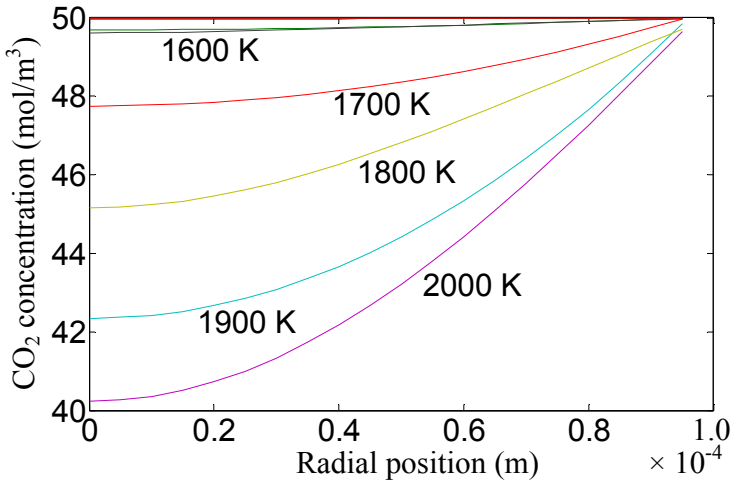

Fig. $6 \mathrm{CO}_{2}$ concentration along radial direction as temperature increases.

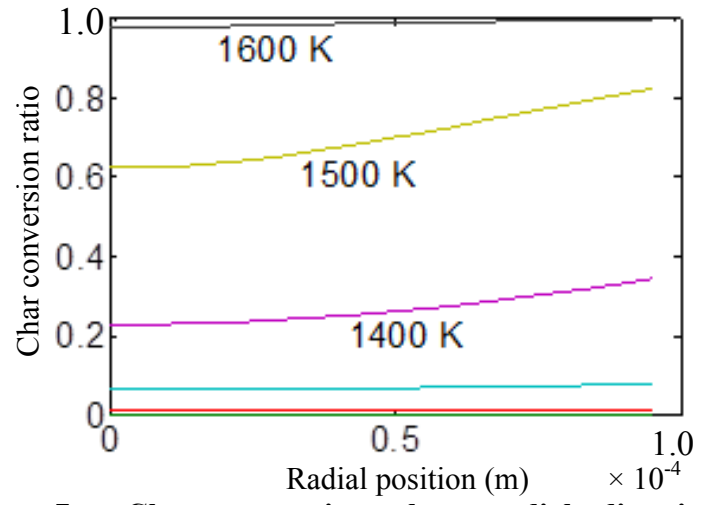

Fig. 7 Char conversion along radial direction as temperature increases. 


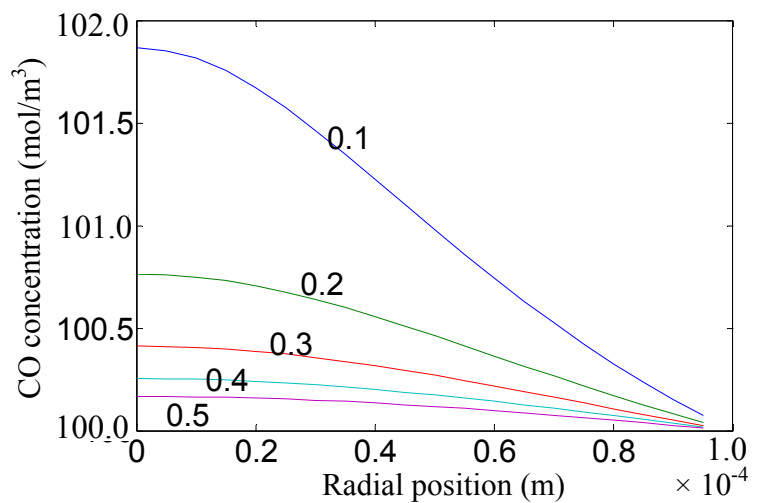

Fig. 8 CO concentration along radial direction for the sensitivity analysis of initial porosity (0.1-0.5).

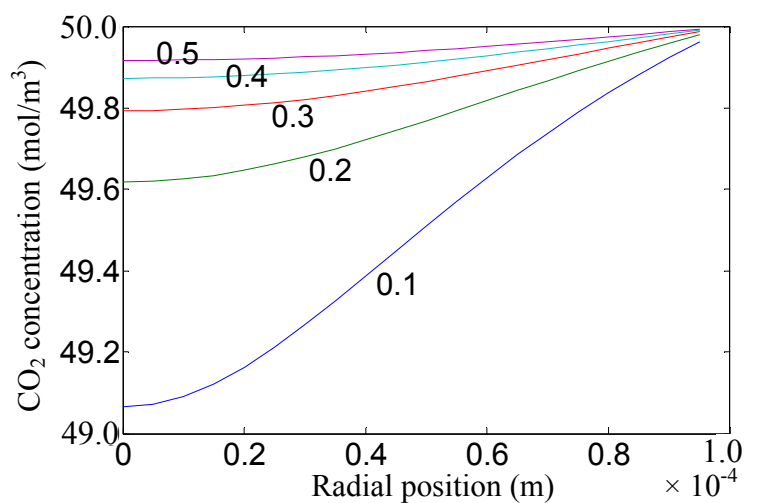

Fig. $9 \mathrm{CO}_{2}$ concentration along radial direction for the sensitivity analysis of initial porosity (0.1-0.5).

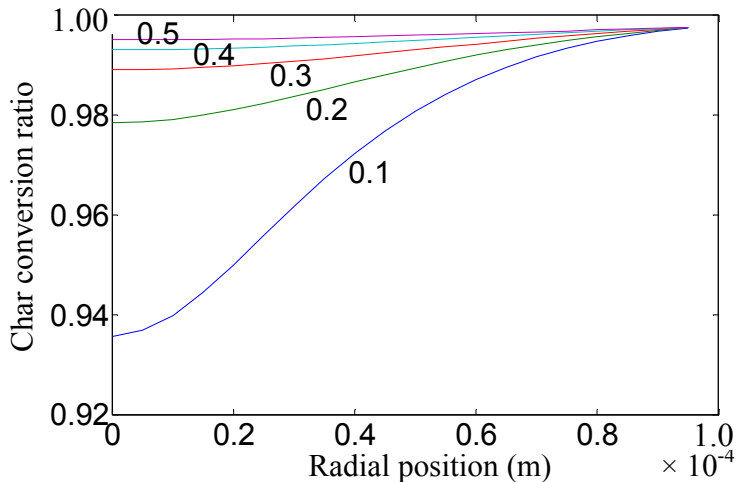

Fig. 10 Char conversion along radial direction for the sensitivity analysis of initial porosity (0.1-0.5).

inside the particle which ultimately increase the amount of $\mathrm{CO}$ produce.

Fig. 9 shows the $\mathrm{CO}_{2}$ concentration for the sensitivity study of initial porosity. It shows that increase in porosity decreases the concentration of $\mathrm{CO}_{2}$ inside the particle. Although the change in concentration inside the particle is considerably low. Fig. 10 shows the char conversion in the radial direction. It shows the increase in porosity of particle increases the char conversion.

\section{Conclusions}

Gasification is one of the important energy conversion methods for the energy production. Although the complexity involved in understanding the chemical kinetics make it very difficult to model and simulate. There are number and variety of models are present in the literature that uses different approach to model the gasification process. In this research, a simplified model is used to simulate the gasification of char particle. The basic idea to develop the model is to build a single reaction mechanism in the form of transport equation with coupled diffusion dependent and reaction source term. The model comprise of two coupled partial differential equations and one ordinary differential equation that are solve simultaneously subjected to proper initial and boundary conditions. The results are calculated for the char particle in the radial direction that simulates the gasification process at high temperature and pressure. It shows that, the concentration of $\mathrm{CO}$ decrease with time and the maximum concentration always lie at the centre of the particle. On the other hand, the concentration of $\mathrm{CO}_{2}$ increase with time and eventually that all the char can be gasified into $\mathrm{CO}$. This is contingent upon the availability of sufficient reaction time or a reduction in the particle size. The sensitivity study of temperature shows that, the concentration of $\mathrm{CO}$ increase as the temperature increase and the concentration of $\mathrm{CO}_{2}$ decrease as the temperature increase. The sensitivity study of initial porosity shows that, it has considerably low effect on char conversion by any increase in it directly proportional to the char particle conversion.

\section{Acknowledgments}

The financial support of MIST (Masdar Institute) and TRC (Takreer Research Centre) is highly acknowledged. 


\section{References}

[1] Bae, J. S., Lee, D. W., Park, S. J., Lee, Y. J., Hong, J. C., and Han, C. 2013. "Synthesis Gas and Char Production from Mongolian Coals in the Continuous Devolatilization Process." Korean Journal of Chemical Engineering 30 (2): 321-6.

[2] Channiwala, S., and Parikh, P. 2002. "A Unified Correlation for Estimating HHV of Solid, Liquid and Gaseous Fuels." Fuel 81 (8): 1051-63.

[3] Syed, I. J. S., and Ghenai, C. 2012. "Thermodynamics Equilibrium Analysis within the Entrained Flow Gasifier Environment." Int. J. of Thermal \& Environmental Engineering 4 (1): 47-54.

[4] Shabbar, S., and Janajreh, I. 2012. "Thermodynamic Equilibrium Analysis of Coal Gasification Using Gibbs Energy Minimization Method." Energy Conversion and Management 65 (January): 755-63.

[5] Janajreh, I., Syed, S., Qudaih, R., and Talab, I. 2010. "Solar Assisted Gasification: Systematic Analysis and Numerical Simulation." Int. J. of Thermal \& Environmental Engineering 1 (2): 81-90.

[6] Janajreh, I., Raza, S. S., and Valmundsson, A. S. 2012. "Plasma Gasification Process: Modeling, Simulation and Comparison with Conventional Air Gasification." Energy Conversion and Management 65 (January): 801-9.

[7] Janajreh, I., and Raza, S. S. 2015. "Numerical Simulation of Waste Tyres Gasification." Waste Management \& Research 33 (5): 460-8.

[8] Adeyemi, I., and Janajreh, I. 2015. "Modeling of the Entrained Flow Gasification: Kinetics-Based ASPEN Plus Model." Renewable Energy 82 (October): 77-84.

[9] Janajreh, I., Raza, S. S., and Elagroudy, S. 2015. "Co-firing of Enteromorpha Prolifera Algae and RTC Coal in a Down Draft Gasifier: Material Characterization and Flow Simulation." The Journal of Solid Waste Technology and Management 41 (1): 68-83.

[10] Kim, Y. T., Seo, D. K., and Hwang, J. 2011. "Study of the Effect of Coal Type and Particle Size on Char- $\mathrm{CO}_{2}$ Gasification via Gas Analysis." Energy \& Fuels 25 (11): 5044-54.

[11] Singer, S. L., and Ghoniem, A. F. 2011. "An Adaptive Random Pore Model for Multimodal Pore Structure Evolution with Application to Char Gasification." Energy \& Fuels 25 (4): 1423-37.

[12] Seo, D. K., Lee, S. K., Kang, M. W., Hwang, J., and Yu, T. U. 2010. "Gasification Reactivity of Biomass Chars with $\mathrm{CO}_{2}$." Biomass and Bioenergy 34 (12): 1946-53.

[13] Suresh, K. R. K., Ahmed, A., and Srinivasakannan, C. 2012. "Gasification Kinetics of Date Palm Seed Using Carbon Dioxide." International Journal of Environmental Research 7 (1): 97-104.

[14] Reid, R. C., Prausnitz, J. M., and Poling, B. E. 1987. The Properties of Gases and Liquids. New York: McGraw-Hill Education. 